\title{
THE ROLE OF LEADER'S SPIRITUAL LEADERSHIP ON ORGANISATION OUTCOMES
}

\author{
Phuong V. Nguyen ${ }^{*}$, Khoa T. Tran', Khanh Hai Dao', and Ho Phi Dinh² \\ ${ }^{1}$ Center for Higher Training and Research in Public Administration, International \\ University, Vietnam National University, Ho Chi Minh City 700000, Vietnam \\ ${ }^{2}$ The School of Business, University of Phan Thiet, Binh Thuan 800000, Vietnam \\ *Corresponding author: nvphuong@hcmiu.edu.vn
}

Published online: 21 December 2018

To cite this article: Phuong, N.V., Khoa, T.T., Khanh, H.D., and Ho, P.D. (2018). The role of leader's spiritual leadership on organisation outcomes. Asian Academy of Management Journal, 23(2), 45-68. https://doi.org/10.21315/aamj2018.23.2.3

To link to this article: https://doi.org/10.21315/aamj2018.23.2.3

\begin{abstract}
This paper aims to investigate a causal model of spiritual leadership theory in organisational context and evaluates the effectiveness of spiritual survival and empowerment on organisational outcomes in terms of commitment and citizenship behaviour. It used structural equation model (SEM) approach to test a conceptual framework with data collection of 329 full-time employees working in service industries in Ho Chi Minh City, Vietnam. The findings illustrated the critical effects of spiritual leadership on organisational outcomes throughout membership, empowerment, and personal characteristics regarding meaning and calling. Specifically, a qualitative approach was conducted to highlight the testing results and get a better understanding of unanticipated consequences from the quantitative analysis. Based on the findings, the study proposed some specific interests of managerial implications and identify some limitations for future study.
\end{abstract}

Keywords: organisational citizenship behaviour, organisational commitment, spiritual leadership, membership, empowerment

\section{INTRODUCTION}

From the past decade, the attention on linking leadership and spirituality, particularly workplace spirituality, has increased considerably. This trend is noticeable when looking at the popular press in the research and literature of business and

(C) Asian Academy of Management and Penerbit Universiti Sains Malaysia, 2018. This work is licensed under the terms of the Creative Commons Attribution (CC BY) (http://creativecommons. org/licenses/by/4.0/). 
management (Fry, 2003; Gotsis \& Kortezi, 2008; Kolodinsky, Giacalone, \& Jurkiewicz, 2008; Pawar, 2009). People, who are considered to have an ability to become leaders, can adequately and efficiently present themselves. Therefore, to thoroughly approach the leadership concept, it is essential to understand the whole of the leader's personality, from his/her body, mind, to emotions and spirituality (Bennis, 2004; Fry, 2003). A connection between leadership and spiritual values has been insightfully exploited and received when scholars integrate the notion of spiritual leadership in the workplace (Fry, 2003; Fry \& Slocum, 2008; Fry, Hannah, Noel, \& Walumbwa, 2011; Wright \& Quick, 2011). They find out substantial evidence to support a significant positive correlation between spirituality and productivity.

In addition, Fry, Vitucci, and Cedillo (2005) identify spiritual leadership is established in an "intrinsic motivation model" that comprises "vision," "hope/ faith," and "altruistic love" to describe a competent leader. Spiritual leadership integrates the behaviours, attitudes, and values of a leader to motivate himself or herself and other persons via spiritual well-being, "calling," and "membership." It enables followers to undergo meaning in their life and feel confident to make a difference. Consequently, the leaders can understand and appreciate the followers' efforts and contributions in the organisation. Furthermore, after conducting a literature review on spiritual values and practices, Reave (2005) illustrates that spiritual leadership at work has generated many inarguable outcomes, which include superior job motivation and satisfaction among workers as the spiritual leadership creates an ethical working environment (Cregård, 2017). Similarly, the empirical researches of spiritual leadership model demonstrate the spiritual leadership has a strong influence on organisational commitment (Fry et al., 2005).

Spiritual leadership is becoming a topic of interest in discussions of the management of organisations for two main reasons. First, organisational managers, who pursue the spiritual leadership model, can create sufficient communications in many differences from cultural contexts and personality traits (Fry, 2003). They can solve the frequent conflicts of religion, ethics, and values at workplace successfully. Second, the leaders with the spiritual style pay more attention to followers' physical and mental well-being (Cregård, 2017). They can motivate employees in a different approach without paying much attention to monetary compensation.

While the previous studies have focused on the impact of spiritual leadership on essential individual and organisational outcomes in a specific country (Fry, 2003; Chen \& Yang, 2012; Fry et al., 2005), to date, a little study has investigated the relationship between spiritual leadership and potential outcomes of organisations 
in an emerging economy like Vietnam. In this paper, we develop a conceptual framework to test hypotheses concerning the positive effect of the spiritual leadership on vital individual and organisational outcomes.

Vietnam has made significant progress in implementing major economic reforms since 1986. As part of this process, it has been attempting to transform from resourced-based and low-skilled labour-intensive production to medium and high technology production. Consequently, the country has successfully attracted foreign direct investment and created incentives for investors to import new technologies and improve the quality and management skills. It not only leads to pressure top managers to adapt to the international requirements, but it also adjusts the leadership styles. But the theory (upper-case government organisations) which often neglects or dismisses the ideas of spiritual leadership needs to catch up with the practical businesses because all leaders in public sectors have to become members of the communist party that formally advocates the ideology of collective leadership communism. Therefore, the spiritual leadership has been newly recognised in society and business environment in Vietnam.

In reality, older leaders, who were born before 1960, have somehow been affected by the collective leadership style of the communist party of Vietnam meanwhile young leaders can apply spiritual leadership approach to be flexible in the dynamic global market to lead to their reputation and aftermarket survival. Therefore, it is imperative for scholars to investigate the role of leader's spiritual leadership in organisational outcomes throughout the mediating linkages among spiritual wellbeing, empowerment, and organisational commitment in Vietnam. This study aims to analyse data collection of 329 full-time employees working in service companies in Ho Chi Minh City, Vietnam. It is worth noting that most companies in Ho Chi Minh City are doing business in service industries. Moreover, the leaders in the service sectors are the young generation, and so they have more opportunities for applying the spiritual leadership model in their companies.

Specifically, to clarify the findings from quantitative method, we also conducted a three-group discussions with nine correspondents (middle managers have been working in the service industries in Ho Chi Minh City, Vietnam). They discussed and shared their experiences and knowledge in their companies about leadership styles and spiritual leadership. We have talked further details of features and characteristics of organisational behaviours in Vietnam in general and these companies in particular. As a result, we understood how leaders motivate the employees. To sum up, when combining both quantitative and qualitative approaches to justify explanations, the findings enable us to suggest insightful interpretations. 
The next section reviews previous studies. To describe and analyse data collection, the two following sections, respectively, provide the methodology and findings of both quantitative and qualitative approaches. The limitations and future studies are derived in the last part.

\section{LITERATURE REVIEW}

\section{Spiritual Leadership}

The spiritual leadership requires managers to decline the past approach of personal leadership that concerned on values of self-interest. These new approaches are strengthened by implicit values concentrating on power, wealth, and prestige (Fairholm, 1996). Instead, in a recent study, Fairholm and Gronau (2015) outline that the spiritual leadership in the workplace is the apprehensive incorporation of the elements of work and personal life into an inclusive approach, which enhances continuous growth, improvement, self-awareness, and self-leadership in such a way that leaders observe each worker as a whole person with a variety of skills, knowledge, and abilities, instead of considering beyond the narrow confines of job requirements.

In addition, several previous studies have found the significant impact of spiritual leadership on essential individual and organisation outcomes (Benefiel, Fry, \& Geigle, 2014; Chen \& Yang, 2012; Fry, Latham, Clinebell, \& Krahnke, 2017; Fry et al., 2005). They identify the linkages among people in organisations in terms of physical, mental, and emotional aspects, but they overlooked the spiritual values. The spiritual leadership enables a learning organisation to become successful throughout creating vision and value congruence across the strategic, empowered team, and individual levels (Fry, 2003). The spiritual leadership is defined as combining the values, attitudes, and behaviours that are essential to motivate followers. Specifically, according to Fry (2003), as the spiritual leadership interacts with vision, hope or faith, and altruistic love lead to motivate followers by spiritual survival through calling and membership. In turn, it has a substantial impact on organisational commitment and productivity as well as corporate outcomes.

After conducting an overview of over 150 previous studies, Reave (2005) proposes that values, that have long been regarded as spiritual ideals such as integrity, honesty, and humility, have been proved to have a substantial impact on leadership success. As a result, these spiritual needs at work have a significantly positive effect on human health and psychological well-being, and establish the foundation for both workplace spirituality and spiritual leadership (Fry et al., 2017). 
Fry (2003) insists that spiritual leadership theory was a reaction to the acquirement for a more encompassing leadership, which was crucial to conjugate the four key areas that characterise the presence of human in the working environment: body (physical), mind (logical/rational thought), heart (emotions, feelings), and spirit. In this theory, "spirituality" implies to the inquiry for self-transcendence and the attendant sense of interconnectedness with all things in the universe (Kriger \& Seng, 2005). Many of characteristics of spirituality in the workplace, the building of society or community, regard to social justice within the organisation and its vision, and equality of voice (Fry et al., 2011; Kriger \& Seng, 2005). Furthermore, prior studies have also identified three components of the spiritual leadership, which include vision, hope or faith, and altruistic love (Fry, 2003; Fry et al., 2005; Chen \& Yang, 2012). The vision refers to a picture of the future with some implicit or explicit commentary on why people should attempt to create that future. Kotter (1996) argued that vision had meaningful effects on the organisations.

Meanwhile, altruistic love in spiritual leadership is defined as "a sense of wholeness, harmony, and well-being produced through care, concern, and appreciation for both self and others" (Fry, 2003). Meanwhile, faith is considered as "more than hope or the expectation of something desired, and it is the conviction that a thing unproved by physical evidence is true" (Fry, 2003). Faith is not only dreaming of something. In other words, faith roots in values, behaviours, and attitudes, which present trust and full belief that what is expected to come. Employees who have hope or faith in a vision are eager to face deterrents and persisting hardships and enduring to accomplish their objectives. Thus, the confidence in the accomplishment of the organisation's vision and mission is a result of hope or faith (Fry, 2003).

\section{Spiritual Well-Being}

In his theory of spiritual leadership, Fry (2003) considers the term of spiritual survival as workplace spirituality, which is composed of calling, also known as being called (vocationally) and a desire for membership or social connection. Calling has been considered as the characteristic to define a professional for a long time. Their ethics, which centered on selfless service to customers, drive them to be responsible for sustaining the quality standards of their profession, dedicate themselves to what they are doing, and commiting to their career. They believe in the values of their business, indeed, even its importance to the society, so being a member of it makes them feel proud. Therefore, calling is the awareness that one is making a difference to others when they create values that serve others' life. As a result, they find their own life's purpose and meaning. One of the leader's responsibilities is to develop a sense of calling in oneself and workers. 
Membership means a sense of being understood and appreciated. People with membership are aware as part of a large community and interrelated with others at work (Babin \& Babin, 2001). When people commit themselves to social groups, they are connected in society by the membership that goes as far when the group experiences power as well as influence. Besides, Chen and Yang (2012) illustrated that if leaders cooperated with employees to create a vision, they would have a sense that their lives and their job were exceptional and had meanings. Through the behaviours of leaders who demonstrate care and altruistic values, a feeling of membership among members will spread throughout the organisation, which creates an organisational culture in which mutual care is valued. Moreover, leaders' care for employees and their confidence in achieving the vision will lead employees to race to it (Chen \& Yang, 2012). In other words, when spiritual leaders "share meaningful visions with employees, and show concern for their values and behavior, the employees feel that their jobs and lives are special and meaningful, resulting in membership" (Chen \& $\mathrm{Li}, 2013$ ).

Spiritual well-being is positively affected by spiritual leadership, when members of a group appreciate and value the sharing of altruistic love, especially as they together build a shared vision, with a hope or faith in that vision, contemporaneously the employees are willing to "do what it takes" to pursue a vision that served vital stakeholders (Fry, 2003). Consequently, spiritual leadership fosters employees' general well-being (Fernando \& Chowdhury, 2010). The engagement to the progress and achievement of a sense of concern and mutual care, critically create a sense of membership among employees. Therefore, we propose two following hypotheses:

H1: Spiritual leadership positively relates to employees' meaning and calling.

H2: Spiritual leadership positively relates to employees' membership.

\section{Empowerment}

Empowerment is often defined as the action of giving people the opportunity to make decisions at work by expanding their autonomy in decision making (Vogt, 1997). It involves the human-resource management by giving them the power and freedom of action, and empowerment means a change of culture and the courage to create and direct an organisational environment. Spreitzer (1995) describes two approaches of empowerment: organisational and psychological empowerments. Corporate empowerment can be interpreted as the structural implementation which stimulates the allocating of the decision-making power and autonomy for the employees and engages them in the actions (Griffith et al., 2010; Peterson 
\& Zimmerman, 2004). Empowerment includes three components: (1) dynamic structure, referring the procurement of rules to encourage basic decision-making of the employees in their work; (2) control of decisions, considering the control of employees over fields of their expert improvement; (3) information fluidity, alluding to the presence of communication channels that enable all individuals to approach the company's information openly and efficiently (Matthews, Michelle Diaz, \& Cole, 2003).

Spiritual leadership applying vision, hope or faith, and altruistic love primarily generates intrinsic motivation among employees through goal identification and task involvement. This process is compelling due to the approach of the higher-order needs of individuals, for instance, self-efficacy, autonomy feeling, relatedness, and competence (Deci \& Ryan, 2000). Throughout the power shared to employees, the effective leaders should not only apply their formal authority to minimise operations costs, but they also need to promote coordination and cooperation within their workforce (Zehnder, Herz, \& Bonardi, 2017). Their capacities and talents that were previously shackled to now have the opportunities to show up. Thus, hypothesis 3 was developed as follows:

H3: Spiritual leadership positively relates to employee empowerment.

\section{Organisational Commitment}

Organisational commitment is considered as when employees have not only the attachment to their job in the organisation, but also have the loyalty and willingness to stay at the company in which values the altruistic love resulting from a sense of calling and membership (Fry, 2003). Meanwhile, productivity and continuous improvement are identified when employees who believe in their organisational vision and have the faith, so the calling and membership are generated to encourage them to "do what it takes" to pursue the vision and continuously improve and be more productive (Fairholm, 1996).

Organisational commitment is an imperative factor in organisational theory due to the solid connections that have been explored in several decades (Cohen, 1993; Kazemipour, Mohamad Amin, \& Pourseidi, 2012; Mathieu \& Zajac, 1990; Mowday, 1998; Rego \& Pina e Cunha, 2008; Srivastava, 2008). The higher commitment employees generate, the better performance; they are likely to work harder with more efficiency and are not willing to leave the organisation. It is best interested in organisations to clutch significant workers and to expand organisational commitment. High degree of organisational commitment is discovered to associate with a low absenteeism degree. 
However, Begley and Czajka (1993) point out that the effect of organisational commitment moderates the impact of stress. When employees obtain a low level of organisational commitment, the employment disappointment will expand because of anxiety is experienced, but when the organisational commitment was high, feeling of stress individuals among people is reduced. Furthermore, other studies showed that positive sense of calling and membership among members would generate their loyalty, attachment, and commitment throughout the organisation. These spiritual well-being are increased by the experience of spiritual leadership in the workplace, an emergent process which is based on shared feeling among team members and eventually creates positive organisational outcomes such as increased organisational commitment (Fry, 2003; Fry et al., 2017). By fulfilling these spiritual acquirements, the leaders generate intrinsic motivation, as well as trust and organisational commitment among members. These outcomes occur when organisation's vision received hope or faith of employees. This progress creates calling and membership for members, and they will put extending attempt and cooperation, which are essential to continuous productivity improvement and key performance index (Benefiel, 2005; Fry \& Slocum, 2008; Fry et al., 2017). Therefore, we proposed two hypotheses:

H4: Meaning/calling positively relates to organisational commitment.

H5: Membership positively relates to organisational commitment.

\section{Organisational Citizenship Behaviour (OCB)}

OCB is defined as "behavior that is discretionary, not directly or explicitly recognised by the formal reward system, and that in aggregate promotes the effective functioning within the organisation," and subsequently contributes "to the maintenance and enhancement of the social and psychological context that supports task performance" (Organ, Podsakoff, \& MacKenzie, 2006). Caring behaviours from leaders towards employees lead to emotional attachment of employees to the organisation. Therefore, they are willing to stay in the organisation. In general, most studies of OCB proposed that "the concepts of workplace spirituality, spiritual leadership, and business models" (Fry et al., 2017) that highlight a balance among employee well-being, employee empowerment, organisational commitment and profitability, and other performance outcomes (Fry et al., 2017; Mayfield \& Mayfield, 2002; Organ et al., 2006).

In the approach to $\mathrm{OCB}$, employees typically engage in two aspects of exchange relationships in their organisation. The first one is the more personal exchanges with co-workers and supervisors, and the second one is the more general exchanges with the larger organisation (Cole, Schaninger, \& Harris, 2002). In spite of the 
different dimensions of OCB that have been distinguished above (Organ et al., 2006; Podsakoff, MacKenzie, Paine, \& Bachrach, 2000), Wat and Shaffer (2005) argue that confidence among empowered employees enables them to initiate and implement OCB. Moreover, these prior studies mention that leadership with empowerment will lead to OCB. Based on these studies, we developed two hypotheses:

H6: Empowerment positively impacts to organisational commitment.

H7: Empowerment positively impacts to OCB.

Scholl (1981) demonstrates that organisational commitment can be viewed to result in OCBs. He argued that it makes employees act continuously in a given manner even when they are not fulfilling what they expect from the organisation. Williams and Anderson (1991) figure out that high level of organisational commitment drives employees willingly to make extra efforts. Therefore, corporate commitment is a crucial antecedent of OCBs. We, therefore, propose the following hypothesis:

H8: Organisational commitment positively impacts to OCB.

Based on the above hypotheses, we developed the conceptual framework as shown in Figure 1.

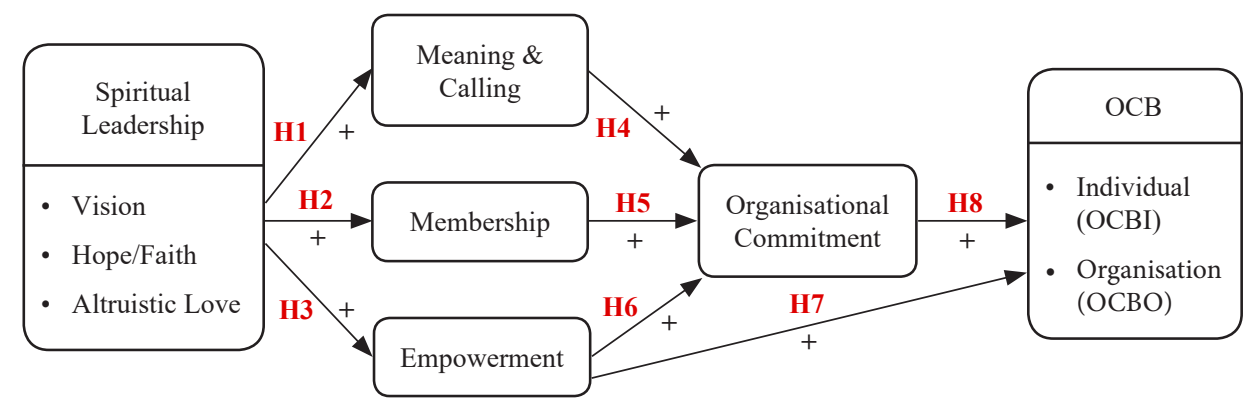

Figure 1. Conceptual framework

\section{METHODOLOGY}

\section{Measurement}

All the measurement scales used for this study were adapted from previous studies (Chen \& Yang, 2012; Fry et al., 2011, 2017, 2005; Hartline \& Ferrell, 1996; Nyhan, 2000; Williams \& Anderson, 1991). Particularly, spiritual leadership 
(a second-order factor) was measured through three subscales including vision, hope or faith, and altruistic love, which were adapted from Fry et al. (2005). These measurement items were confirmed by Chen and Yang (2012). The next two constructs of meaning and calling, and membership were followed from Fry et al. (2005). The empowerment construct was developed by Hartline and Ferrel (1996). The organisational commitment construct was developed and validated by Nyhan (2000), and this measurement was utilised and confirmed by Fry et al. (2005). The measurement of OCB, which is a second-order factor and includes two components of organisational citizenship behaviour individual (OCBI) and organisational citizenship behaviour organisation (OCBO), was adopted from William and Anderson (1991) (see Appendix).

First, we translated all questions from English to Vietnamese and it was examined and corrected by an English lecturer. However, the first Vietnamese version was not easy readable and understandable. Secondly, we conducted a pilot test with 30 participants during three weeks in January 2016. Therefore, the final version was improved after the pilot test. The results collected from the pilot test enabled us to verify and modify the Vietnamese questionnaire for easy understanding and answer under the Vietnamese context. For instance, it took at least five times to revise and clarify the meaning of spiritual leadership in Vietnamese. The participants also suggested how to translate survey items and make them different from other statements.

The questionnaire included two parts. Part I asks about demographics of the participants such as type and scale of enterprises, job titles, and so on. Meanwhile, Part II presents questions relating to the measurement constructs of the conceptual framework (see Appendix). We use a 5-point Likert scale ranging from " 1 = strongly disagree" to " $5=$ strongly agree" to measure these items. The participants were instructed to answer the questionnaire. It is worth noting that the current study uses second-order factor analysis to test the conceptual framework.

\section{Participants}

It took three months to collect the questionnaire survey from February to April 2016. In the initial plan, we attempt to collect data of correspondents, who were working in both service and manufacturing sectors in Ho Chi Minh City, Vietnam. However, most of the heavy manufacturing industries have been moved out of downtown districts in recent years. Hence, we only focused on the service industries. 
By using the snowball sampling method with the support from the business community in Ho Chi Minh City, we have not only contacted with managers in retailing service industries (for instance, Co.opmart and Big C group, which are two incumbent suppliers in the supply-chain industry in Ho Chi Minh City); but also asked managers for assistance from the financial and banking sector (for example, BIDV, Vietcombank, and Vietinbank, which are among the largest commercial banks in Vietnam). These managers have introduced us to their branches in 10 downtown districts to deliver the questionnaire survey to the target employees. Notably, these branches are operating independently, in terms of recruitment and sales activities. We selected two retailing supermarkets and three commercial banks in each downtown district. As a result, we dropped 10 hard copies of questionnaires in each place, and total 500 questionnaires were delivered to the target correspondents. We waited for one week to come back to receive the survey responses. It is worth mentioning that we had to stop by each place several times to collect data. Finally, we received 415 responses. However, after eliminating incomplete questionnaires, we only used 329 valid responses from full-time employees who were working with service industries in Ho Chi Minh City.

The number of male and female groups from the sample is nearly equal, which are $55 \%$ and $45 \%$, respectively. In other aspects of demographics, the result shows that majority of the correspondents are from 25 to 35 years old (56\%), and have university educational level (55.6\%) and less than three years working experiences $(59.9 \%)$.

In the qualitative method, we conducted three in-depth interviews. We invited nine correspondents (middle managers who have been working in the service industries in Ho Chi Minh City) to participate in three groups to discuss and share their own experiences in their companies about leadership styles and spiritual leadership. We have talked further details of features and characteristics of organisational behaviours in Vietnam in general and their companies in particular. Specifically, we also explored how leaders in their companies motivate the employees. Besides, we also shared our quantitative results and asked for their opinions and recommendations. 


\section{RESULTS}

\section{Reliability and Construct Validity}

First, Table 1 presents the descriptive statistics of data collected, including the mean and standard deviation. Moreover, in terms of the reliability, all the Cronbach's alphas of the variables are over 0.7 , and the corrected item-total correlations of all items are over than 0.3 , which confirms the reliability of the measurement requirements (George \& Mallery, 2003).

Second, an exploratory factor analysis (EFA) was implemented which served to "reduce the number of variables as the measurement indicators for the path analysis of overall model" (Lee, 2009). In this step, the principal axis factoring was conducted to extract and develop factors in the structural equation model (SEM). As suggested by Hair, Anderson, Tatham, and Black (1998), only items with a factor loading larger than 0.5 were chosen. Kaiser-Meyer-Olkin (KMO) is a criterion used for assessing the appropriateness of factor analysis, and it is widely accepted that a KMO from at least 0.5 to 1 indicates proper factor analysis. Based on these criteria, the results of EFA test led to eliminating the following items: HOP1, MEM1, EMP5, EMP6, COM1, and OCBI4. In fact, these six items were deleted because of their confused meanings in the Vietnamese context. In other words, they sound similar to the other items in the same measurement of each identified factor. Therefore, for future studies, adopting these initial measurement and translating them into other languages will be a primary challenge in making each dimension differentiated with the rest.

Table 1

Data description and reliability analysis

\begin{tabular}{lccccc}
\hline $\begin{array}{l}\text { Variables } \\
\text { (First-order factors) }\end{array}$ & $\begin{array}{c}\text { Variables } \\
\text { (Second-order factors) }\end{array}$ & $\begin{array}{c}\text { Numbers } \\
\text { of items }\end{array}$ & $\begin{array}{c}\text { Cronbach's } \\
\text { alpha }\end{array}$ & Mean & $\begin{array}{c}\text { Standard } \\
\text { deviation }\end{array}$ \\
\hline Spiritual leadership & Vision & 5 & 0.830 & $3.27-3.49$ & $0.75-0.91$ \\
& $\begin{array}{l}\text { Hope or faith } \\
\text { Altruistic love }\end{array}$ & 4 & 0.806 & $3.56-3.74$ & $0.77-0.78$ \\
& & 6 & 0.865 & $3.25-3.42$ & $0.89-0.97$ \\
Meaning \& calling & & 4 & 0.855 & $3.62-3.92$ & $0.73-0.81$ \\
Membership & & 6 & 0.805 & $3.07-3.72$ & $0.75-0.87$ \\
Empowerment & & 4 & 0.831 & $3.40-3.72$ & $0.82-0.96$ \\
Organisational & & & 0.841 & $3.31-3.43$ & $0.68-0.74$ \\
$\quad$ commitment & OCBI & 4 & 0.784 & $3.54-3.91$ & $0.77-0.84$ \\
OCB & OCBO & 3 & 0.768 & $3.99-4.24$ & $0.77-0.86$ \\
\hline
\end{tabular}


Third, the construct validation of the spiritual leadership model is performed by the confirmatory factor analysis (CFA). Table 2 illustrates various fit indexes, which are utilised to test the model fit. All of the results display the consistency with the model based on the criteria of Hair, Anderson, Tatham, and Black (2010). For instance, the Chi-square/df (CMIN/df) is smaller than 1.0, goodness-of-fit index (GFI) is close to 0.9; comparative fit index (CFI) and Tucker-Lewis Index (TLI) are all greater than 0.9 with the root mean square error of approximation (RMSEA) is less than 0.05 .

Table 2

The model fit of measuring model

\begin{tabular}{lcccccc}
\hline Measure & CMIN/df & GFI & AGFI & CFI & TLI & RMSEA \\
\hline Total samples (329) & 1.521 & 0.883 & 0.858 & 0.948 & 0.940 & 0.040 \\
Thresholds & $\leq 2^{* *}$ & $\geq 0.9^{* *}$ & $\geq 0.8^{*}$ & $\geq 0.9^{* *}$ & $\geq 0.9^{*}$ & $\leq 0.05^{* *}$ \\
& $\leq 3^{*}$ & $\geq 0.8^{*}$ & & & & $\leq 0.08^{*}$ \\
\hline
\end{tabular}

Note: ${ }^{* *}$ good, ${ }^{*}$ moderate; AGFI $=$ adjusted GFI

\section{Convergent Validity and Discriminant Validity}

To test the convergent validity of a measurement scale, two indicators are considered: average variance extracted (AVE) and composite reliability (CR). The minimum value of AVE should be at least 0.5 , but when $C R$ is larger than 0.6 , the minimum amount of AVE is 0.4 , it can be accepted due to assuring the construct convergent validity (Fornell \& Larcker, 1981). After conducting the CFA test in the first round, the convergent validity did not meet these criteria. Therefore, two items (ALT3 and VIS5 of Appendix 1) were dropped out.

Table 3 shows that all estimates and AVEs of all factors are higher than 0.5 and CR values of all factors are good $(>0.7)$. In other words, the convergent validities of all constructs are confirmed, and the reliability for all constructs and items of this model is completely satisfied the criteria.

We used the correlation between two constructs to measure the discriminant validity. When the AVE of each measurement item is higher than the square of biggest correlation estimates of that factor with other factors (maximum shared variance), the discriminant validity is certified (Fornell \& Larcker, 1981). Table 3 presents the satisfaction of all factors to the mentioned standards. 
Phuong V. Nguyen et al.

Table 3

Convergent and discriminant validity

\begin{tabular}{|c|c|c|c|c|c|c|c|c|c|c|c|c|c|}
\hline & CR & AVE & MSV & ASV & OCBI & ALT & VIS & MEAN & EMP & $\mathrm{COM}$ & MEM & OCBO & HOP \\
\hline OCBI & 0.806 & 0.582 & 0.312 & 0.168 & 0.763 & & & & & & & & \\
\hline ALT & 0.846 & 0.524 & 0.460 & 0.216 & 0.321 & 0.724 & & & & & & & \\
\hline VIS & 0.812 & 0.521 & 0.165 & 0.086 & 0.215 & 0.273 & 0.722 & & & & & & \\
\hline MEAN & 0.860 & 0.608 & 0.272 & 0.190 & 0.403 & 0.392 & 0.340 & 0.780 & & & & & \\
\hline EMP & 0.824 & 0.540 & 0.224 & 0.146 & 0.473 & 0.457 & 0.204 & 0.419 & 0.735 & & & & \\
\hline $\mathrm{COM}$ & 0.845 & 0.579 & 0.460 & 0.249 & 0.442 & 0.678 & 0.295 & 0.513 & 0.350 & 0.761 & & & \\
\hline MEM & 0.800 & 0.502 & 0.398 & 0.234 & 0.413 & 0.631 & 0.341 & 0.522 & 0.468 & 0.568 & 0.709 & & \\
\hline OCBO & 0.778 & 0.540 & 0.312 & 0.133 & 0.559 & 0.215 & 0.200 & 0.405 & 0.296 & 0.410 & 0.295 & 0.735 & \\
\hline HOP & 0.787 & 0.554 & 0.376 & 0.213 & 0.361 & 0.536 & 0.406 & 0.465 & 0.297 & 0.613 & 0.531 & 0.400 & 0.744 \\
\hline
\end{tabular}

Notes: MSV = maximum shared variance; $\mathrm{ASV}=$ average shared variance; $\mathrm{OCBI}=$ organisational citizenship behaviour - individual; $\mathrm{ALT}=$ altruistic love VIS = vision; $\mathrm{MEAN}=$ meaning and calling; $\mathrm{EMP}=$ empowerment $\mathrm{COM}=$ organisational commitment MEM $=$ membership; $\mathrm{OCBO}=$ organisational citizenship behaviour - organisation; HOP $=$ hope/faith. Both ALT3 and VIS5 were dropped out. Square root of AVE on bold/diagonal.

\section{Measurement Model Validation}

The results of testing SEM approach meet the criteria of model fit, with Chisquare/degree of freedom $=1.634, \mathrm{GFI}=0.869, \mathrm{TLI}=0.927, \mathrm{CFI}=0.869$, and RMSEA $=0.044$ (Hair et al., 2010). Figure 2 illustrates the estimated coefficients with denoting significant levels from testing results of SEM technique. Almost all of the estimated coefficients in SEM are strongly significant $(p<0.01)$ and different from each other, except for the estimated coefficient of "empowerment" to "organisational commitment" has a $p$-value equal to 0.593 and greater the threshold value of 0.10 (the maximum requirement). Therefore, except for H6, the remaining hypotheses are empirically supported.

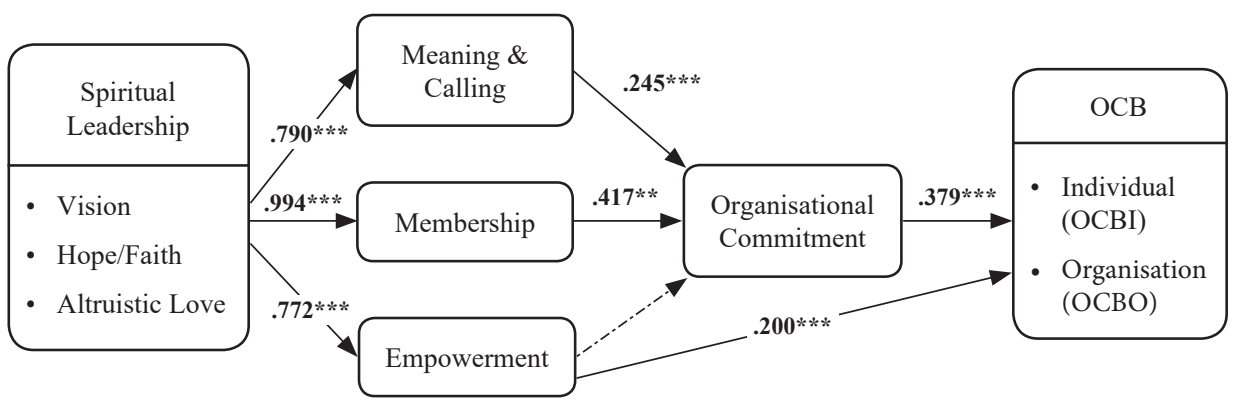

Figure 2. The results of hypothesis testing Note: ${ }^{*} p<0.05 ;{ }^{* *} p<0.01 ;{ }^{* * *} p<0.001$; a dashed line is not statistically significant 


\section{DISCUSSION}

We concluded the present findings with several objectives in remarks. First, we wanted to investigate whether the measurement of spiritual leadership could be applied from other cultures to Vietnamese culture in the service industries. Second, we developed the conceptual framework to test the research hypotheses. Third, we discussed the findings from the quantitative analysis and then combined the results from the qualitative study to provide insight explanations. These discussions were described as follows.

Firstly, H6 is not supported. It implies that empowerment does not influence organisational commitment. The result is not consistent with previous studies (Menon, 2001; Wat \& Shaffer, 2005).

Secondly, based on the significant level, H1, H2, and H3 were supported (all three $p$-values $<0.001$ ). Generally speaking, these findings are consistent with previous studies (Chen \& Yang, 2012; Fry et al., 2005; Jeon, Passmore, Lee, \& Hunsaker, 2013). Specifically, the estimates of the effect of spiritual leadership on membership, meaning and calling, and empowerment were 0.994, 0.790, and 0.772 , respectively. Obviously, the spiritual leadership had the most significant impact on membership than the two other factors.

Thirdly, $\mathrm{H} 3$ and $\mathrm{H} 4$ were supported with $p$-values $<0.001$. The loading estimate of membership (0.417) is higher than that of meaning and calling (0.245). According to Porter, Steers, Mowday, and Boulian (1974), organisational commitment is considered as the high level of one's identification and involvement with a specific organisation. By strong feeling of membership within the organisation, employees understandably have a high sense of loyalty and attachment to the organisation.

Fourthly, H8 is supported with a $p$-value $<0.001$ and positive estimate from organisational commitment to $\mathrm{OCB}(0.379)$. The finding is consistent with previous studies (Podsakoff et al., 2000; Srivastava, 2008) and spiritual leadership has an indirect effect to OCB via in turn followers' spiritual survival (meaning and calling, and membership) and organisational commitment. With above relationships, we can infer that there is an existing indirect relationship between spiritual leadership effectiveness and extra-role behaviours.

The research has partially developed the spiritual leadership model. Indeed, it is more likely to generalise the current situation of the spiritual leadership execution in Vietnam. This is different from other countries in terms of values, cultures, and business characteristics. Vietnam, although experience different conditions in other 
developed countries, witnessed the apparent impact of spiritual leadership factors in the organisation outcomes, which confirmed the current effects of spiritual leadership in the service industries. Moreover, the development of the model is showed through the added variables, empowerment, and OCB. Empowerment, despite its smaller coefficient compared to meaning and membership, has been confirmed as an essential aspect of spiritual leadership, which shed new light on mediating impact of spiritual leadership on OCB. However, it has no significant effect on organisational commitment. To provide a meaningful explanation, it is necessary to combine with the qualitative results.

Although empowerment has no impact on organisational commitment, it has a statistically significant effect on OCB. The findings are not entirely consistent with previous studies (Griffith et al., 2010; Peterson \& Zimmerman, 2004). Specifically, Avolio, Zhu, Koh, and Puja (2004) proved that psychological empowerment played an essential role in mediation relationship between organisational commitment and transformational leadership. However, with the results of group discussions, the participants help us to explain why empowerment has no significant impact on our model. Indeed, most company leaders in Vietnam are not willing to grant formal authorities and legal power to their employees or staffs. Most Vietnamese employees have no autonomy to solve issues. Whenever there are any problems, they have to report to the supervisor, and then the supervisor will refer to the manager for the solution. In many cases, the manager has to ask the director to make a final decision. Moreover, in state-owned enterprises, the process to get the approval will take a long time and is complicated because of bureaucracy.

In group discussions, all participants had the same opinion that although Vietnamese employees have not been receiving more autonomy, they are willing to support and share responsibilities with their colleagues (building up a personal relationship or OCBI). For instance, Participant 9 emphasised that Vietnam is lacking a well-developed legal system; people of society believe more in their connections, rather than the rule of law. Thus, the higher level of organisational commitment would associate more with OCBI.

Specifically, from the theoretical implications, the study insights some interests of managerial implementations. Companies should consider the spirituality at the workplace and coordinate this value into the leadership because the employees always attempt to enhance the value of their working environment throughout discovering significance in their job as well as obtaining the more meaningful and happy life than just receiving a salary (Benefiel, 2005). The finding also confirms the theory withdraws from Fairholm and Gronau (2015) that "when leaders think about the leadership they do, these managers do not shy away from discussions 
that relate to morality, values, inspiration, individual wholeness, organizational concern for individual growth and development, stewardship, and service."

Moreover, as a result of discussion group 1, all participants agreed that based on the fundamental performance index of employees, leaders have to understand their employees' needs and wants. For instance, Participant 1 stated that he often took his subordinates to dine out at an excellent restaurant. It created happiness environment after they completed a project. They felt good to be recognised and accountable for their work and willing to share their family stories or opinion out of daily jobs. Other interviewees (Participants $1 \& 2$ ) also had a similar idea of offline meetings. Notably, if subordinates were invited to have a working lunch or working dinner after these meetings, it was an excellent opportunity for innovating new business ideas or finding appropriate solutions.

Leaders and managers should attend some short training courses to identify and reflect themselves about whom they are, who the company is, and what the company is contributing to the social responsibilities. Therefore, leaders can be actively aware that their leadership is crucial for employees. They will be motivated to coach subordinates by oozing a feeling of self-efficacy and offering them fairness and justice, and meaningful and valued work. Furthermore, leaders should share the company vision, mission, and values to all employees. Leaders should create effective procedures to receive employee's feedback and recommendations when they encounter business problems or operational issues. Consequently, they will create and innovate the better motivation policy to ensure that company leaders consider employees as members, who also deliver the mindset. When having an ordinary asset, everyone builds the success together and shares the achievements, both tangible (profits, bonus, opportunities for future projects) and intangible ones (reputation, feeling of success). As a result of discussion group 2, all participants (Participants 4, $5 \& 6$ ) had a similar opinion that leaders should attend short courses or seminars of leadership skills. For instance, Participant 5 stated that she often registered for a workshop on leadership techniques and soft skills to improve her ability to motivate employees to balance their job and life.

Furthermore, in the service industries, the nature of the job is intense and easy to make mistakes because they work with many different types of customer, so they often deal with high levels of stress, nervous, and tension. Leaders can apply the values of spiritual leadership to reduce the fear, anxiety, and explain how important they are in such a whole sophisticated system. For instance, in the group discussions, all participants agreed that leaders should provide short training courses to improve communication skills that enable employees to deal with the customers as thoroughly as possible. 
Last but not least, the care and altruistic love of spiritual leaders can inspire employees in the service sectors. Individuals need to feel associated with each other as members of an association or group. Open discussion between leaders and members about their concerns/problems each month, having outdoor activities, entertainment competition, sharing pictures and information of company's events are suggested to apply spiritual leadership to build membership. These activities generate the essential role of the organisation towards employees' life so that the company becomes an utmost importance to them. As for suggestions of group 3 (Participants 7, $8 \&$ 9), the leaders should not build boundaries to restrict their subordinates, instead of empowering employees to feel that they are devoting more time and effort to achieve the company target. Also, all participants agree that good leaders should be good listeners, optimistic, happy, and whole-hearted as they are in their minds. Leaders should care about the work and the teammates, and always listen to different opinions to make the appropriate decision for everyone to work together.

\section{CONCLUSION}

The paper investigated the validity of spiritual leadership theory throughout the organisational context of 329 participants, who were working in service industries in 10 downtown districts of Ho Chi Minh City, Vietnam. We found that spiritual leadership had a significant relationship with meaning and calling, membership, and empowerment. This study also showed that meaning and membership had a positive impact on organisational commitment and then, in turn, it had a substantial effect on OCB. Membership presents the most impacted factor of spiritual leadership and the most profound antecedent of organisational commitment, compared to meaning and empowerment. Empowerment had a positive influence on OCB but has no statistical effect on organisational commitment. Combining with the qualitative method, we received essential feedbacks, which help us to explain the quantitative results clearly and appropriate scenarios in the Vietnamese context.

\section{Limitations and Future Study}

There exist some research limitations such as uncovered factors influencing the spiritual leadership, self-evaluated based research, and research scale. We recommend the future studies should explore the originated Western leadership style and Confusion values in Vietnam so that they can construct a new conceptual model to combine the self-based and leaders' assessment and focus on some specific groups. Moreover, the translation from the original measurements of initial 
factors to other languages should be aware of confused meanings. Researchers may consider to eliminate the similar items or modify to differentiate them before conducting the survey. Specifically, the future study should also expand in different industries, religions, and locations in Vietnam to highlight the differences. Finally, future research should be conducted across cultures and in different countries to highlight the universality of the construct of spiritual leadership.

\section{APPENDIX}

\section{Survey Items}

\section{Vision}

I understand and am committed to my organisation's vision (VIS1).

My workgroup has a vision statement that brings out the best in me (VIS2).

My organisation's vision inspires my best performance (VIS3).

I have faith in my organisation's vision for its employees (VIS4).

My organisation's vision is clear and compelling to me (VIS5).

\section{Hope/Faith}

I have faith in my organisation, and I am willing to do whatever it takes to ensure that it accomplishes its mission (HOP1).

I persevere and exert extra effort to help my organisation succeed because I have faith in what it stands for (HOP2).

I always do my best in my work because I have faith in my organisation and its leaders (HOP3).

I set challenging goals for my work because I have faith in my organisation and want us to succeed (HOP4).

\section{Altruistic Love}

My organisation really cares about its people (ALT1).

My organisation is kind and considerate towards its workers, and when they are suffering, wants to do something about it (ALT2).

The leaders in my organisation - walk the walk\| as well as - talk the talk (ALT3).

My organisation is trustworthy and loyal to its employees (ALT4).

The leaders in my organisation are honest and without false pride (ALT5).

The leaders in my organisation have the courage to stand up for their people (ALT6).

\section{Meaning/Calling}

The work I do is very important to me (MEAN1).

My job activities are personally meaningful to me (MEAN2).

The work I do is meaningful to me (MEAN3).

The work I do makes a difference in people's lives (MEAN4). 


\section{Membership}

I feel my organisation understands my concerns (MEM1).

I feel my organisation appreciates me, and my work (MEM2).

I feel highly regarded by my leadership (MEM3).

I feel I am valued as a person in my job (MEM4).

I feel my organisation demonstrates respect for me, and my work (MEM5).

\section{Empowerment}

My leader allows me to complete freedom in my work (EMP1).

My leader permits me to use my own judgment in solving problems (EMP2).

My leader encourages initiative (EMP3).

My leader lets me do my work the way I think best (EMP4).

My leader assigns task, then let me handle them (EMP5).

My leader trusts me to exercise good judgment (EMP6).

\section{Organisational Commitment}

I do feel like part of the family in this organisation (COM1).

I would be very happy to spend the rest of my career with this organisation (COM2).

I talk up this organisation to my friends as a great place to work for (COM3).

I feel as if my organisation's problems are my own (COM4).

\section{Organisational Citizenship Behaviour - Individual}

I help others who have heavy workloads (OCBI1).

I take time to listen to co-workers' problems and worries (OCBI2).

I go out of my way to help new employees (OCBI3).

I assist my supervisor with his/her work even when I am not asked (OCBI4).

\section{Organisational Citizenship Behaviour - Organisation}

My attendance at work is above the norm (OCBO1).

I obey informal rules that developed to maintain order (OCBO2).

I give notice when I am unable to come to work (OCBO3). 


\section{REFERENCES}

Avolio, B.J., Zhu, W., Koh, W., \& Puja, B. (2004). Transformational leadership and organizational commitment: Mediating role of psychological empowerment and moderating role of structural distance. Journal of Organizational Behavior, 25(May), 951-968. https://doi.org/10.1002/job.283

Babin, B.J., \& Babin, L. (2001). Seeking something different? A model of schema typicality, consumer affect, purchase intentions and perceived shopping value. Journal of Business Research, 54(2), 89-96. https://doi.org/10.1016/S01482963(99)00095-8

Begley, T., \& Czajka, J. (1993). Panel analysis of the moderating effects of commitment on job-satisfaction, intent to quit, and health following organizational-change. Journal of Applied Psychology, 78(4), 552-556. https://doi.org/10.1037//00219010.78.4.552

Benefiel, M. (2005). The second half of the journey: Spiritual leadership for organizational transformation. Leadership Quarterly, 16(5), 723-747. https://doi.org/10.1016/j. leaqua.2005.07.005

Benefiel, M., Fry, L.W., \& Geigle, D. (2014). Spirituality and religion in the workplace: History, theory, and research. Psychology of Religion and Spirituality, 6(3), 175187. https://doi.org/10.1037/a0036597

Bennis, W.G. (2004). On becoming a leader. Reading: Addison Wesley.

Chen, C.-Y., \& Yang, C.-F. (2012). The impact of spiritual leadership on organizational citizenship behavior: A multi-sample analysis. Journal of Business Ethics, 105(1), 107-114. https://doi.org/10.1007/s10551-011-0953-3

Chen, C.Y., \& Li, C.I. (2013). Assessing the spiritual leadership effectiveness: The contribution of follower's self-concept and preliminary tests for moderation of culture and managerial position. Leadership Quarterly, 24(1), 240-255. https://doi.org/10.1016/j.leaqua.2012.11.004

Cohen, A. (1993). Organizational commitment and turnover: A meta-analysis. The Academy of Management Review, 36(5), 1140-1157. https://doi.org/10.2307/256650

Cole, M.S., Schaninger, W.S., \& Harris, S.G. (2002). The workplace social exchange network: A multilevel, conceptual examination. Group and Organization Management, 27(1), 142-167. https://doi.org/10.1177/1059601102027001008

Cregård, A. (2017). Investigating the risks of spiritual leadership. Nonprofit Management and Leadership, 27(4), 533-547. https://doi.org/10.1002/nml.21262

Deci, E.L., \& Ryan, R.M. (2000). The "what" and "why" of goal pursuits: Of behavior human needs and the self-determination. Psychological Inquiry, 11(4), 227-268. https://doi.org/10.1207/S15327965PLI1104_01

Fairholm, G.W. (1996). Spiritual leadership: Fulfilling whole-self needs at work. Leadership \& Organization Development Journal, 17(5), 11-17. https://doi. org/10.1108/01437739610127469

Fairholm, M.R., \& Gronau, T.W. (2015). Spiritual leadership in the work of public administrators. Journal of Management, Spirituality \& Religion, 12(4), 354-373. https://doi.org/10.1080/14766086.2015.1060516 
Fernando, M., \& Chowdhury, R.M.M.I. (2010). The relationship between spiritual wellbeing and ethical orientations in decision making: An empirical study with business executives in Australia. Journal of Business Ethics, 95(2), 211-225. https://doi.org/10.1007/s10551-009-0355-y

Fornell, C., \& Larcker, D.F. (1981). Evaluating structural equation models with unobservable variables and measurements error. Journal of Marketing Research, 18(4), 39-50. https://doi.org/10.2307/3151312

Fry, L.W. (2003). Toward a theory of spiritual leadership. The Leadership Quarterly, 14(6), 693-727. https://doi.org/10.1016/j.leaqua.2003.09.001

Fry, L.W., Hannah, S.T., Noel, M., \& Walumbwa, F.O. (2011). Impact of spiritual leadership on unit performance. The Leadership Quarterly, 22(2), 259-270. https://doi.org/10.1016/j.leaqua.2011.02.002

Fry, L.W., Latham, J.R., Clinebell, S.K., \& Krahnke, K. (2017). Spiritual leadership as a model for performance excellence: A study of Baldrige award recipients. Journal of Management, Spirituality and Religion, 14(1), 22-47. https://doi.org/10.1080/ 14766086.2016.1202130

Fry, L.W., \& Slocum, J.W. (2008). Maximizing the triple bottom line through spiritual leadership. Organizational Dynamics, 37(1), 86-96. https://doi.org/10.1016/j. orgdyn.2007.11.004

Fry, L.W., Vitucci, S., \& Cedillo, M. (2005). Spiritual leadership and army transformation: Theory, measurement, and establishing a baseline. The Leadership Quarterly, 16(5), 835-862. https://doi.org/10.1016/j.leaqua.2005.07.012

George, D., \& Mallery, P. (2003). SPSS for Windows step by step: A simple guide and reference, 11.0 update. Boston, MA: Allyn \& Bacon. https://doi.org/10.1177/ 1073191112446654

Gotsis, G., \& Kortezi, Z. (2008). Philosophical foundations of workplace spirituality: A critical approach. Journal of Business Ethics, 78(4), 575-600. https://doi. org/10.1007/s10551-007-9369-5

Griffith, D.M., Allen, J.O., Deloney, E.H., Robinson, K., Lewis, E.Y., Campbell, B., Morrel-Samuels, S., Sparks, A., Zimmerman, M.A., \& Reischl, T. (2010). Community-based organizational capacity building as a strategy to reduce racial health disparities. The Journal of Primary Prevention, 31(1-2), 31-39. https://doi.org/10.1007/s10935-010-0202-Z

Hair, J.F., Anderson, R.E., Tatham, R.L., \& Black, W.C. (1998). Multivariate data analysis with readings (5th ed.). Upper Saddle River, NJ: Prentice-Hall.

Hair, J.F., Anderson, R.E., Tatham, R.L., \& Black, W.C. (2010). Multivariate data analysis: A global perspective (7th ed.). New Jersey: Pearson Prentice-Hall. https://doi. org/10.1016/j.jmva.2009.12.014

Hartline, M.D., \& Ferrell, O.C. (1996). The management of service employees: An empirical investigation. Journal of Marketing, 60(4), 52-70. https://doi.org/ $10.2307 / 1251901$

Jeon, K.S., Passmore, D.L., Lee, C., \& Hunsaker, W. (2013). Spiritual leadership: A validation study in a Korean context. Journal of Management, Spirituality \& Religion, 10(4), 342-357. https://doi.org/10.1080/14766086.2013.801026 
Kazemipour, F., Mohamad Amin, S., \& Pourseidi, B. (2012). Relationship between workplace spirituality and organizational citizenship behavior among nurses through mediation of affective organizational commitment. Journal of Nursing Scholarship, 44(3), 302-310. https://doi.org/10.1111/j.1547-5069.2012.01456.x

Kolodinsky, R.W., Giacalone, R.A., \& Jurkiewicz, C.L. (2008). Workplace values and outcomes: Exploring personal, organizational, and interactive workplace spirituality. Journal of Business Ethics, 81(2), 465-480. https://doi.org/10.1007/ s10551-007-9507-0

Kotter, J.P. (1996). Leading change. Harvard Business Review, 187. https://doi.org/ 10.1007/s13398-014-0173-7.2

Kriger, M., \& Seng, Y. (2005). Leadership with inner meaning: A contingency theory of leadership based on the worldviews of five religions. Leadership Quarterly, 16(5), 771-806. https://doi.org/10.1016/j.leaqua.2005.07.007

Lee, T.H. (2009). A structural model to examine how destination image, attitude, and motivation affect the future behavior of tourists. Leisure Sciences, 31(3), 215236. https://doi.org/10.1080/01490400902837787

Mathieu, J.E., \& Zajac, D.M. (1990). A review and meta-analysis of the antecedents, correlates, and consequences of organizational commitment. Psychological Bulletin, 108(2), 171-194. https://doi.org/10.1037/0033-2909.108.2.171

Matthews, R.A., Michelle Diaz, W., \& Cole, S.G. (2003). The organizational empowerment scale. Personnel Review, 32(3), 297-318. https://doi.org/10.1108/ 00483480310467624

Mayfield, J., \& Mayfield, M. (2002). Leader communication strategies critical paths to improving employee commitment. American Business Review, 20(2), 89-94.

Menon, S. (2001). Employee empowerment: An integrative psychological approach. Applied Psychology, 50(1), 153-180. https://doi.org/10.1111/1464-0597.00052

Mowday, R.T. (1998). Reflections on the study and relevance of organizational commitment. Human Resource Management Review, 8(4), 387-401. https://doi. org/10.1016/S1053-4822(99)00006-6

Nyhan, R.C. (2000). Changing the paradigm: Trust and its role in public sector organizations. The American Review of Public Administration, 30(1), 87-109. https://doi.org/10.1177/02750740022064560

Organ, D.W., Podsakoff, P.M., \& MacKenzie, S.B. (2006). Organizational citizenship behavior: Its nature, antecedents and consequences. Personnel Psychology, 59(2), 457-500. https://doi.org/10.1111/j.1744-6570.2006.00043_9.x

Pawar, B.S. (2009). Workplace spirituality facilitation: A comprehensive model. Journal of Business Ethics, 90(3), 375-386. https://doi.org/10.1007/s10551-009-0047-7

Peterson, N.A., \& Zimmerman, M.A. (2004). Beyond the individual: Toward a nomological network of organizational empowerment. American Journal of Community Psychology, 34(1-2), 129-145. https://doi.org/10.1023/B:AJCP. 0000040151.77047 .58

Podsakoff, P.M., MacKenzie, S.B., Paine, J.B., \& Bachrach, D.G. (2000). Organizational citizenship behaviors: A critical review of the theoretical and empirical literature and suggestions for future research. Journal of Management, 26(3), 513-563. https://doi.org/10.1177/014920630002600307 
Porter, L.W., Steers, R.M., Mowday, R.T., \& Boulian, P.V. (1974). Organizational commitment, job satisfaction, and turnover among psychiatric technicians. Journal of Applied Psychology, 59(5), 603-609. https://doi.org/10.1037/h0037335

Reave, L. (2005). Spiritual values and practices related to leadership effectiveness. The Leadership Quarterly, 16(5), 655-687. https://doi.org/10.1016/j.leaqua. 2005.07.003

Rego,A., \& Pina e Cunha. M.(2008). Workplace spirituality and organizational commitment: An empirical study. Journal of Organizational Change Management, 21(1), 5375. https://doi.org/10.1108/09534810810847039

Scholl, R.W. (1981). Differentiating organizational commitment from expectancy as a motivating force. The Academy of Management Review, 6(4), 589. https://doi. org $/ 10.2307 / 257637$

Spreitzer, G.M. (1995). Psychological empowerment in the workplace: Dimensions, measurement, and validation. Academy of Management Journal, 38(5), 14421465. https://doi.org/10.2307/256865

Srivastava, S. (2008). Organizational citizenship behaviour as a function of organizational commitment and corporate citizenship in organizations. Management and Labour Studies, 33(3), 311-337. https://doi.org/10.1177/0258042X0803300301

Vogt, P. (1997). Transfer to power. Credit Union Management, 20(6), 44-45.

Wat, D., \& Shaffer, M.A. (2005). Equity and relationship quality influences on organizational citizenship behaviors: The mediating role of trust in the supervisor and empowerment. Personnel Review, 34, 406-422. https://doi.org/ $10.1108 / 00483480510599752$

Williams, L.J., \& Anderson, S.E. (1991). Job satisfaction and organizational commitment as predictors of organizational citizenship and in-role behaviors. Journal of Management, 17(3), 601-617. https://doi.org/10.1177/014920639101700305

Wright, T.A., \& Quick, J.C. (2011). The role of character in ethical leadership research. The Leadership Quarterly, 22(5), 975-978. https://doi.org/10.1016/j. leaqua.2011.07.015

Zehnder, C., Herz, H., \& Bonardi, J.P. (2017). A productive clash of cultures: Injecting economics into leadership research. The Leadership Quarterly, 28(1), 65-85. https://doi.org/10.1016/j.leaqua.2016.10.004 